\title{
Effects of quercetin and arginine on the nephrotoxicity and lipid peroxidation induced by gold nanoparticles in vivo
}

This article was published in the following Dove Press journal: International Journal of Nanomedicine

\section{Mohamed Anwar K \\ Abdelhalim \\ Huda AY Qaid \\ Yanallah Al-Mohy \\ Mohammed Suliman Al-Ayed}

Department of Physics and

Astronomy, College of Science,

King Saud University, Riyadh,

Saudi Arabia
Correspondence: Mohamed Anwar K Abdelhalim

Department of Physics and Astronomy, College of Science, King Saud University Riyadh, P.O. Box 2655 Riyadh II45I, Saudi Arabia

Email abdelhalimmak@yahoo.com; mabdulhleem@ksu.edu.sa
Introduction: This study aimed to evaluate the nephrotoxicity caused by gold nanoparticles (GNPs) and investigate the potential roles of quercetin (Qur) and arginine (Arg) in mitigating the inflammatory kidney damage and dysfunction and inhibiting the toxicity induced by GNPs in rats. Methods: Kidney function was assessed using various serum biomarkers, including blood urea nitrogen (BUN), uric acid (URIC), and creatinine (CR), while toxicity was evaluated by measuring the biomarkers glutathione (GSH) and malondialdehyde (MDA) in kidney tissues.

Results: Administration of GNPs to the rats severely affected the serum kidney biomarkers, as confirmed by the notable increases in BUN, URIC, and CR. Substantial changes in the levels of the biomarkers MDA and GSH in the kidney tissues were also observed, with a reduced level of GSH and elevated MDA activity. The administration of Qur or Arg exerted a protective effect against GNP-induced inflammatory kidney damage and toxicity, but with different responses according to their evaluated normalized values.

Conclusion: This study demonstrates the beneficial effects of supplementation with Qur or Arg during the treatment with GNPs, potentially providing a powerful tool for cancer therapy.

Keywords: gold nanoparticles, nephrotoxicity, lipid peroxidation, inflammatory damage, natural antioxidants

\section{Introduction}

The use of nanoparticles (NPs) is not only restricted to the manufacturing industry and medical science, but it is also becoming increasingly common in consumer products. ${ }^{1}$ The increased surface reactivity of NPs has been considered the main reason for their toxicity. ${ }^{2,3}$ The small size of NPs affords a large specific surface area and permits high affinity to be attained in biological systems. However, previous studies have indicated that increasing the surface area of NPs substantially promotes the generation of ROS., ${ }^{4,5}$

The shape and characteristics of gold nanoparticles (GNPs) make them promising materials for a broad range of biological applications. However, the application of GNPs in medicine and drug delivery requires a comprehensive understanding of their bioaccumulation and systemic toxicity. The kidneys are highly susceptible to xenobiotics owing to their extensive blood supply and capability to the toxins. ${ }^{6,7}$ Despite the numerous beneficial applications of GNPs, several studies have demonstrated that smaller GNPs cause greater cytotoxic and inflammatory responses compared with larger GNPs at the same mass concentration, ${ }^{6,7}$ owing to their high reactivity with biological components and the adverse effects induced by their enormous surface area and the large number of NPs. ${ }^{6,7}$ 
The toxicity of GNPs is influenced by their composition, nature of the functional surface, and shape and size. ${ }^{6-8}$ Exposure to GNPs may result in cardiac tissue damage, thickening and scarring of connective tissues, and long-term inflammatory cell infiltration, depending on the GNP size and period of exposure. ${ }^{6-8}$ These effects may originate from tissue damage due to the GNP toxicity, interactions of the GNPs with amino acids and enzymes, interference with the antioxidant resistance system, increased production of ROS, and induction of stress in kidney cells followed by necrosis. ${ }^{6,7}$

Quercetin (Qur) shields cells against oxidative stress and calcium dysregulation induced by hydrogen peroxide. ${ }^{8}$ Arginine (Arg) is a conditionally essential amino acid that plays several important roles in the body, such as mitosis, wound healing, and defense against infectious substances. ${ }^{9-11}$

To the best of our knowledge, no studies into the prevention of the nephrotoxicity induced by small GNPs have yet been reported. The goals of this study were to confirm the occurrence of GNP-induced nephrotoxicity and evaluate the protective effects of Qur or Arg supplementation in mitigating the toxicity, lipid peroxidation, and oxidative stress caused by GNPs, in an effort to support the potential application of GNPs in cancer treatment.

\section{Methods}

\section{GNPs and antioxidants}

Ten-nanometer GNPs (MKN-Au-010; MK IPEX Corp, Divn MK Nano, Canada) with a spherical shape according to transmission electron microscopy (TEM) images were used in this study. The rats were intraperitoneally administered $50 \mu \mathrm{L}$ of the $10 \mathrm{~nm}$ GNPs. The GNP dose was selected according to the results obtained in our previous studies, ${ }^{6,7}$ where we used 10,20 , and $50 \mathrm{~nm}$ GNPs and demonstrated that the smallest GNPs exhibited the highest toxicity in most of the organs of the rats, which was confirmed by histological investigations. Quercetin (Qur) and arginine (Arg) were purchased from Sigma-Aldrich Co. (St Louis, MO, USA). The Qur and Arg doses were $100 \mathrm{mg} / \mathrm{kg}$ body weight (BW)/day and $200 \mathrm{mg} / \mathrm{kg}$ $\mathrm{BW} /$ day, respectively, which were selected according to the previous studies..$^{12,13}$

\section{Animals}

Twenty-four Wistar Kyoto rats (12-week-old males weighing 220-240 g) were obtained from the College of Pharmacy at King Saud University (KSU). The rats were placed in cages under stable conditions $\left(22^{\circ} \mathrm{C} \pm 5^{\circ} \mathrm{C}\right.$ temperature, $55 \% \pm 5 \%$ humidity, and 12-hour light/dark cycle). The rats were allowed free access to water and fed with standard diet chow.
All of the procedures involving animals were approved by the ethics committee at KSU and strictly followed.

\section{Experimental design}

The rats were fasted for 24 hours prior to administration of the GNPs and then separated into four groups of six rats. The first group (G1) of rats was not administered GNPs, which served as a control. The second group (G2) of rats was administered a daily intraperitoneal dose of $50 \mu \mathrm{L}$ of $10 \mathrm{~nm}$ GNPs for 7 days. The third group (G3) of rats was administered a daily intraperitoneal dose of $50 \mu \mathrm{L}$ of $10 \mathrm{~nm}$ GNPs plus $100 \mathrm{mg} / \mathrm{kg}$ BW/day of Qur for 7 days. The fourth group (G4) of rats was administered a daily intraperitoneal dose of $50 \mu \mathrm{L}$ of $10 \mathrm{~nm}$ GNPs plus $200 \mathrm{mg} / \mathrm{kg} \mathrm{BW/day} \mathrm{of} \mathrm{Arg} \mathrm{for} 7$ days. ${ }^{12,13} \mathrm{We}$ previously showed that histological changes in various rat organs are dependent on both the size of the GNPs and the duration of exposure, and these changes were observed after 7 days. ${ }^{6}$

\section{Blood sampling and tissue preparation}

The rats were deprived of food for 12-14 hours, and the serum samples were centrifuged at 3,000 rpm for 10 minutes and stored at $-80^{\circ} \mathrm{C}$ prior to analysis of the serum biomarkers. The kidney tissues were harvested via midline incision, rinsed with cold isosmotic saline, and homogenized with ice at $-80^{\circ} \mathrm{C}$ prior to analysis of the tissue biomarkers. ${ }^{13}$

\section{Serum kidney function biomarkers}

The blood urea nitrogen (BUN), creatinine (CR), and uric acid (URIC) values in the blood serum of the rats were assayed using a biochemical auto-analyzer (Type 7170; Hitachi Ltd., Tokyo, Japan). ${ }^{13}$

\section{Reduced glutathione (GSH) level}

The GSH level in the kidney tissues was determined enzymatically using the revised technique reported by Griffith. ${ }^{14}$ The kidney tissues were first homogenized in $0.2 \mathrm{M}$ ice-cold perchloric acid containing $0.01 \%$ EDTA followed by centrifugation at 10,000 rpm for 5 minutes. To evaluate the GSH level, the same procedures used by Abdelhalim et al were applied. ${ }^{13}$ The absorbance was measured at a wavelength of $412 \mathrm{~nm}$ after 120 minutes at a temperature of $30^{\circ} \mathrm{C}$. The GSH activity was determined by comparing the difference in absorbance between the test solution and a glutathione standard. ${ }^{13}$

\section{Malondialdehyde (MDA) level}

The MDA level in the kidney tissues of the test animals was determined spectrophotometrically as a lipid peroxidation biomarker index, as reported by Utley et al. ${ }^{28}$ The tissues 
were weighed and then homogenized $(10 \% \mathrm{w} / \mathrm{v})$ in $0.15 \mathrm{M}$ frozen potassium chloride $(\mathrm{KOH})$ inside a Potter homogenizer equipped with a motor-driven Teflon pestle. ${ }^{13}$ Samples $(1 \mathrm{~mL})$ of the tissue homogenate were incubated in a shaker at a temperature of $37^{\circ} \mathrm{C}$ for 2 hours. Aliquots $(1 \mathrm{~mL})$ of the supernatant were added to $1 \mathrm{~mL}$ portions of $0.67 \%(\mathrm{w} / \mathrm{v})$ 2-thiobarbituric acid, and the resulting mixtures were placed in a hot water bath for 10 minutes, allowed to cool by adding $1 \mathrm{~mL}$ of distilled water. The absorbance was measured at a wavelength of $535 \mathrm{~nm}$, and using the tetraethoxypropane, the MDA level was determined. ${ }^{13}$

\section{Statistical analysis}

The results are presented as the mean $\pm \mathrm{SE}$ and were subjected to one-way ANOVA. The confidence level was assayed $(* P<0.05$ and $* * P<0.001)$ compared with the control rats (a) and the rats administered GNPs (b).

\section{Results}

Figure 1 shows that the serum CR level of the GNPs group $(0.57 \pm 0.02 \mathrm{mg} / \mathrm{dL})$ was higher than that of the control group $(0.43 \pm 0.03 \mathrm{mg} / \mathrm{dL})$. The GNPs+Qur and GNPs+Arg groups displayed significantly reduced serum CR levels of $0.43 \pm 0.02 \mathrm{mg} / \mathrm{dL}$ and $0.45 \pm 0.02 \mathrm{mg} / \mathrm{dL}$, respectively. Thus, treatment of the rats with Qur or Arg in addition to the GNPs maintained the serum CR level near that of the control animals.

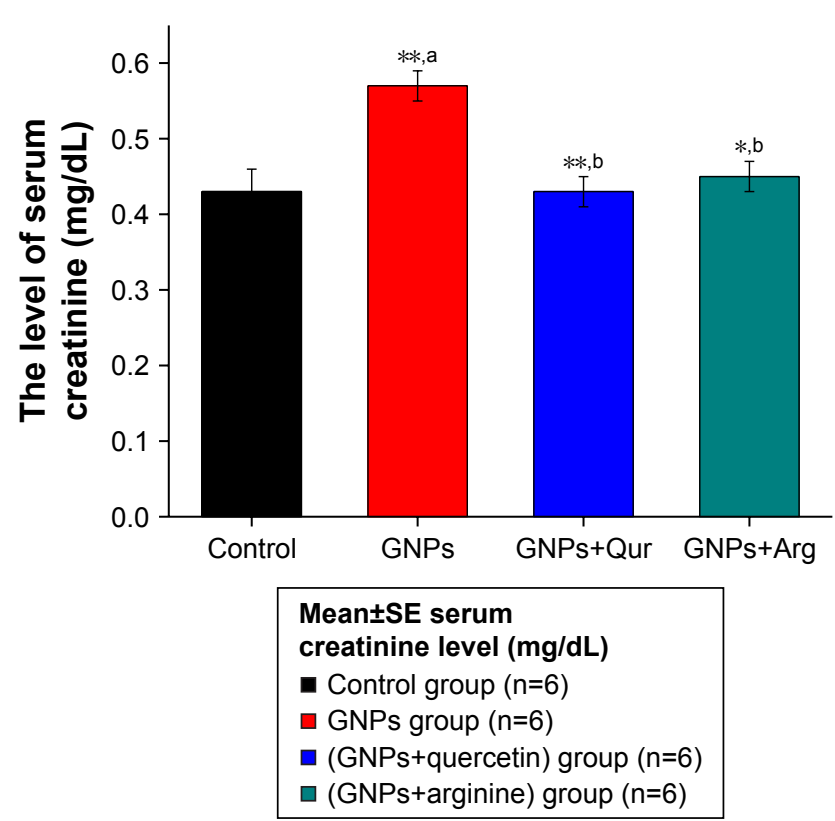

Figure I Effects of GNPs, GNPs+Qur, and GNPs+Arg on the serum creatinine levels of the rats.

Notes: a Compared with control group. ${ }^{b}$ Compared with GNPs group. $* P<0.05$ and $* * \mathrm{p}<0.0$ I.

Abbreviations: Arg, arginine; GNPs, gold nanoparticles; Qur, quercetin; SE, standard error.
Figure 2 shows the serum BUN levels of the control, GNPs, GNPs+Qur, and GNPs+Arg groups. The serum BUN level of the control rats was $18.08 \pm 0.93 \mathrm{mg} / \mathrm{dL}$. Following 7 days of intraperitoneal administration of the GNPs, the mean serum BUN level had increased significantly to $23.28 \pm 1.03 \mathrm{mg} / \mathrm{dL}$ $(* * P<0.01)$, reflecting a marked disturbance of the normal urea level, leading to renal damage. Supplementation with Qur or Arg significantly reduced the BUN levels to $18.52 \pm 0.88 \mathrm{mg} / \mathrm{dL}$ and $19.22 \pm 0.62 \mathrm{mg} / \mathrm{dL}$, respectively.

Figure 3 shows that the serum URIC level of the GNPs group $(1.55 \pm 0.75 \mathrm{mg} / \mathrm{dL})$ was higher than that of the control group $(1.10 \pm 0.98 \mathrm{mg} / \mathrm{dL})$. Supplementation with Qur or Arg significantly reduced the serum URIC levels to $1.10 \pm 0.45$ $\mathrm{mg} / \mathrm{dL}$ and $1.13 \pm 0.65 \mathrm{mg} / \mathrm{dL}$, respectively.

Figure 4 shows that the GSH level in the kidney tissues of the GNPs group $(24.20 \pm 0.02 \mu \mathrm{g} / \mathrm{mL})$ notably decreased when compared with the control group $(56.85 \pm 0.02 \mu \mathrm{g} / \mathrm{mL})$. Supplementation with Qur $(47.85 \pm 0.01 \mu \mathrm{g} / \mathrm{mL})$ or Arg $(46.47 \pm 0.02 \mu \mathrm{g} / \mathrm{mL})$ almost restored the GSH to normal levels.

Figure 5 shows that the MDA level in the kidney tissues of the GNPs group $(0.27 \pm 0.03 \mu \mathrm{mol} / \mathrm{mL})$ markedly increased compared with the control group $(0.08 \pm 0.01 \mu \mathrm{mol} / \mathrm{mL})$. Supplementation with Qur or Arg effectively decreased the MDA levels to $0.15 \pm 0.03 \mu \mathrm{mol} / \mathrm{mL}$ and $0.94 \pm 0.02 \mu \mathrm{mol} / \mathrm{mL}$, respectively.

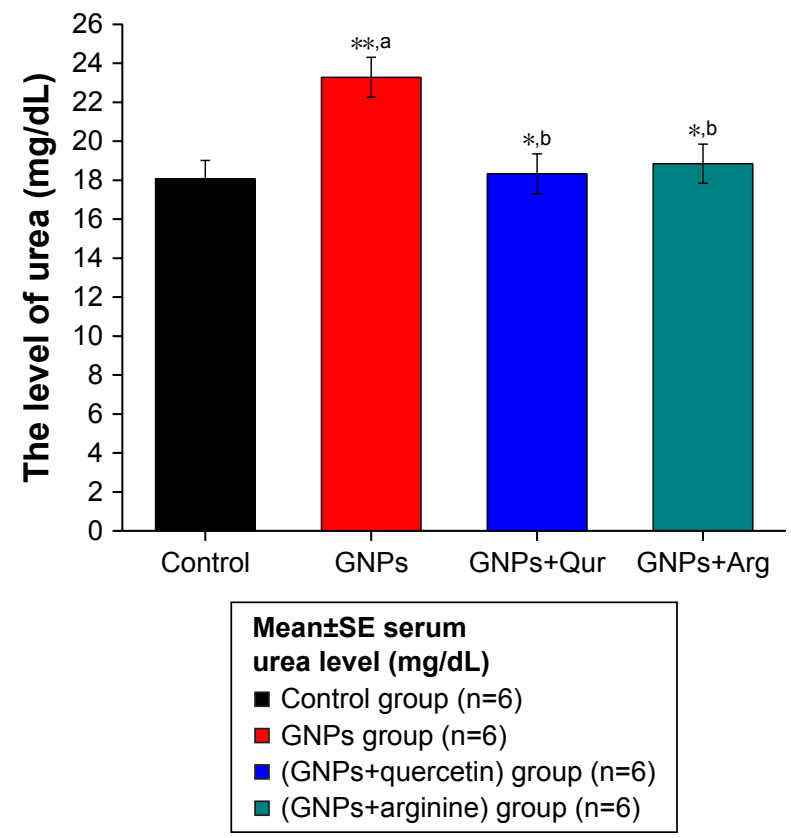

Figure 2 Effects of GNPs, GNPs+Qur, and GNPs+Arg on the serum blood urea nitrogen levels of the rats.

Notes: a Compared with control group. ${ }^{b}$ Compared with GNPs group. ${ }^{*} P<0.05$ and $* * P<0.01$.

Abbreviations: Arg, arginine; GNPs, gold nanoparticles; Qur, quercetin; SE, standard error. 


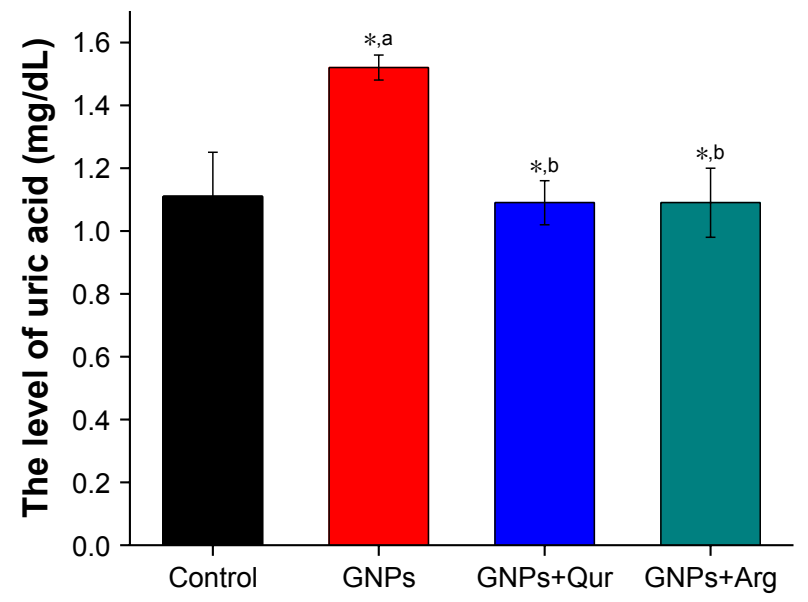

\begin{tabular}{|l|}
\hline Mean \pm SE \\
uric acid level $(\mathbf{m g} / \mathbf{d L})$ \\
- Control group $(n=6)$ \\
$\square$ GNPs group $(n=6)$ \\
(GNPs+quercetin) group $(n=6)$ \\
(GNPs+arginine) group $(n=6)$
\end{tabular}

Figure 3 Effects of GNPs, GNPs+Qur, and GNPs+Arg on the serum uric acid levels of the rats.

Notes: ${ }^{a}$ Compared with control group. ${ }^{b}$ Compared with GNPs group. ${ }^{*} P<0.05$ Abbreviations: Arg, arginine; GNPs, gold nanoparticles; Qur, quercetin; SE, standard error.

\section{Discussion}

It has been established that nanoparticles enter blood vessels and associated tissues that supply blood and then spread to the hepatocytes, spleen, and kidneys. ${ }^{15,16}$ The kidneys play an

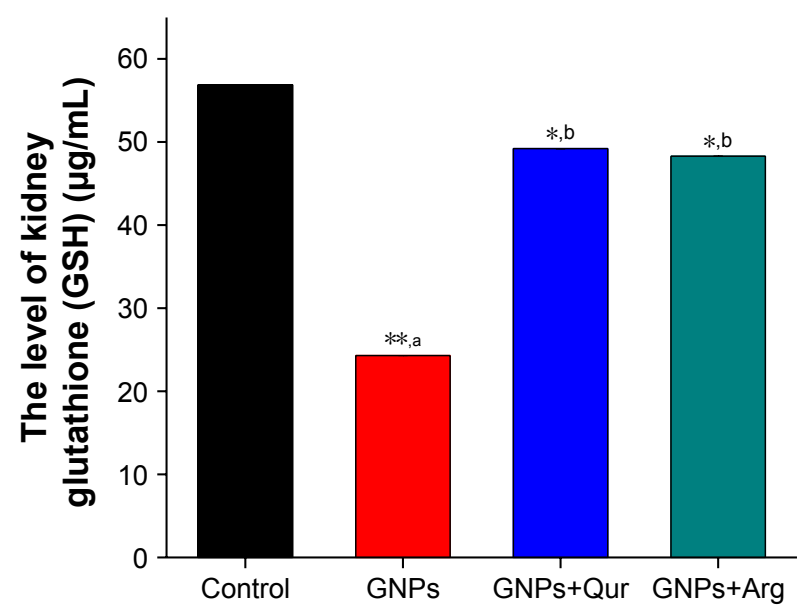

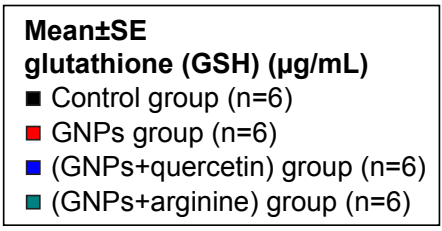

Figure 4 Effects of GNPs, GNPs+Qur, and GNPs+Arg on the kidney glutathione levels of the rats.

Notes: a Compared with control group. ${ }^{b}$ Compared with GNPs group. $* P<0.05$ and $* * P<0.01$.

Abbreviations: Arg, arginine; GNPs, gold nanoparticles; Qur, quercetin; SE, standard error.

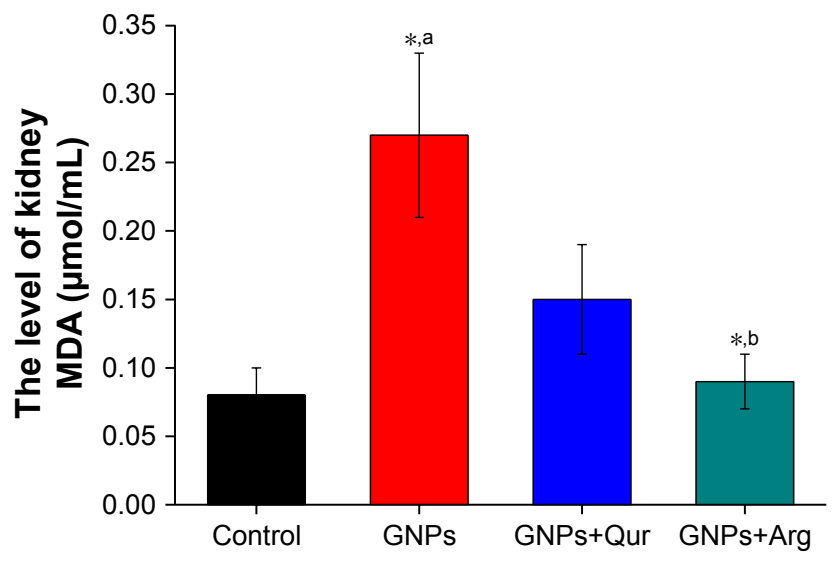

\begin{tabular}{|l|}
\hline Mean \pm SE malondialdehyde \\
(MDA)( $\mu$ mol/mL) \\
- Control group $(n=6)$ \\
$\square$ GNPs group $(n=6)$ \\
(GNPs+quercetin) group $(n=6)$ \\
$\square($ GNPs+arginine) group $(n=6)$
\end{tabular}

Figure 5 Effects of GNPs, GNPs+Qur, and GNPs+Arg on the kidney MDA levels of the rats.

Notes: a Compared with control group. ${ }^{b}$ Compared with GNPs group. $* P<0.05$. Abbreviations: Arg, arginine; GNPs, gold nanoparticles; MDA, malondialdehyde; Qur, quercetin; SE, standard error.

essential role in removing toxic substances from the body. The NPs absorbed in the blood vessels and the associated tissues (which the blood vessels supply) are discharged by renal clearance. ${ }^{17,18}$

Only a few researchers have reported the possibility of NPs being poisonous to the renal tubules and glomeruli., ${ }^{4} 19$ Kidney injury with structural, pathological, and cell-like modifications resulting in kidney failure caused by NPs has been reported..$^{20,21}$ In this study, the intraperitoneal administration of GNPs in vivo was found to significantly increase the serum levels of CR, URIC, and BUN compared with the control group. Furthermore, administration of the GNPs resulted in a significant increase in the MDA level and a significant decrease in the GSH level in kidney tissues.

Both Qur and Arg were found to exert protective effects against these GNP-mediated changes, opposing the imbalance due to the creation of free radicals and interference with the antioxidant resistance system, suggesting that these antioxidants may have medical applications against the cell-like destruction by preventing the accumulation of ROS.22

It has been established that Qur significantly decreases cytokine levels, suggesting its usefulness for decreasing transplant knock-back. These results may explain the previous findings that the administration of Qur decreased tubular damage and mitigated the increase in inflammatory cytokine levels. ${ }^{23}$

In this study, Arg significantly attenuated the increase in the CR level caused by the injection of the GNPs. Arg is 
known to possess several important biological and defensive functions, which are mainly related to inflammation and oxidative stress. ${ }^{24}$ It plays a protective role against inflammation and oxidative stress in various pathological settings. ${ }^{22}$

Upon treatment with Qur, the serum nitrate level significantly decreased in the intoxicated animals. However, the increased nitrogen oxide level in the Arg-treated group was complemented by a notable increase in the kidney GSH content of the rats injected with GNPs. The group injected with GNPs displayed a noteworthy increase in the lipid peroxidation biomarker MDA, which might be associated with the generation of free radicals and consequent destruction of renal tissue, as indicated by the increased levels of kidney function biomarkers. ${ }^{25}$

In this study, the administration of GNPs significantly decreased the GSH level, whereas supplementation with Qur or Arg almost completely restored the GSH to normal levels. The antioxidant capacity of Qur is predominantly due to its ability to react with hydrogen peroxide, ${ }^{26}$ and it also decreases platelet agglomeration and crosslinking by reducing hydrogen peroxide accumulation. ${ }^{27}$ Qur may also decrease cyclosporine-triggered oxidative stress by restoring the activities of antioxidative enzymes including glutathione peroxidase and catalase, thus inhibiting the nephrotoxic activity of cyclosporine and the resulting renal destruction. ${ }^{27}$

Owing to the established relationship between NPs and oxidative stress, one plausible consequence of GNP-induced oxidative stress is DNA destruction. ROS have been reported to combine with DNA molecules resulting in damage to both purine and pyrimidine bases as well as the DNA backbone. ${ }^{25}$ Moreover, mitigation of oxidative stress by either Qur or Arg may also mediate their anti-inflammatory effects. The GSH level in kidney tissues decreased significantly after administration of GNPs, whereas treatment with either Qur or Arg restored the GSH level in kidney tissues, which was ascribed to the antioxidant ability of the two compounds.

It has been observed that Arg causes a significant increase in the MDA level and a decrease in the GSH content in rat cardiac tissues. ${ }^{24}$ These findings support the present results where the two antioxidants significantly ameliorated kidney damage by increasing the cellular GSH level and reducing lipid peroxidation and serum kidney biomarkers. These results were substantiated by histological examination of renal tissues, which revealed the breaking up of numerous glomeruli, renal tubules, and massive and average atrophy, including epithelial degeneration and necrosis. Co-administration of Qur or Arg alongside the GNPs greatly reduced the occurrence of most of these histopathological features. ${ }^{24}$
These results demonstrate that GNPs may cause inflammatory kidney injury through the generation of inflammatory mediators. Therefore, protective agents that reduce the production of these inflammatory mediators could mitigate the renal destruction and prevent organ failure. As shown in this study, supplementation with Qur or Arg was useful for inhibiting the GNP-induced nephrotoxicity as well as the resulting kidney dysfunction and inflammatory damage.

The MDA level is the primary index of lipid peroxidation; MDA acts as a carcinogenic and mutagenic substance, and when it combines with DNA, it forms a compound containing deoxyguanosine, deoxyadenosine, and deoxycytidine. ${ }^{25}$ This DNA destruction can activate signal transduction pathways, inducing apoptosis and ultimately resulting in cell death. ${ }^{25}$ The supplementation of Qur or Arg to rats administered GNPs helped protect their kidneys from DNA damage. The results of this study indicate that the protective effects of Qur or Arg against oxidative stress, lipid peroxidation, and kidney inflammatory damage and dysfunction may be associated with their capacity to restore these parameters to their normal levels.

\section{Conclusion}

This study confirmed the nephrotoxic effects of GNPs, which induced significant increases in the serum levels of $\mathrm{CR}$, BUN, and URIC as well as significant elevation of the MDA level and a reduction of the GSH level in kidney tissues. Supplementation with Qur or Arg successfully mitigated the nephrotoxicity and lipid peroxidation induced by the GNPs. Our results confirm the protective effects of Qur and Arg as highly potent antioxidants, as well as their ability to mitigate kidney dysfunction and shield kidney tissues against the effects of lipid peroxidation and oxidative stress.

\section{Acknowledgment}

The authors would like to extend their sincere appreciation to the Deanship of Scientific Research at King Saud University for the funding of this research through the research Group Project No RGP-285.

\section{Author contributions}

MAKA devises and participated in designing the study. MAKA and HAYQ carried out the bench work of the research and analyzed the role of the antioxidants in nephrotoxicity, lipid peroxidation, and inflammatory kidney injury. MAKA, YA, MSA, and HAYQ were involved in the research design and statistical analysis of research data. All authors contributed to data analysis, drafting and revising the article, 
gave final approval of the version to be published, and agree to be accountable for all aspects of the work.

\section{Disclosure}

The authors report no conflicts of interest in this work.

\section{References}

1. van Tassel KA, Goldman R. The growing consumer exposure to oxidative stress and mitochondrial damage. Environ Health Perspect. 2003; 111:455-460.

2. Donaldson K, Tran L, Jimenez LA, et al. Combustion-derived nanoparticles: a review of their toxicology following inhalation exposure. Part Fibre Toxicol. 2005;2:10.

3. Colvin VL. The potential environmental impact of engineered nanomaterials. Nat Biotechnol. 2003;21(10):1166-1170.

4. Møller P, Jacobsen NR, Folkmann JK, et al. Role of oxidative damage in toxicity of particulates. Free Radic Res. 2010;44(1):1-46.

5. Li N, Sioutas C, Cho A. Ultrafine particulate pollutants induce nanotechnology in everyday product: regulating innovative technologies in light of lessons from the past. Connecticut Law Review. 2011;44:2.

6. Abdelhalim MA, Jarrar BM. Renal tissue alterations were size-dependent with smaller ones induced more effects and related with time exposure of gold nanoparticles. Lipids Health Dis. 2011;10:163.

7. Abdelhalim MA. Gold nanoparticles administration induces disarray of heart muscle, hemorrhagic, chronic inflammatory cells infiltrated by small lymphocytes, cytoplasmic vacuolization and congested and dilated blood vessels. Lipids Health Dis. 2011;10:233.

8. Wang H, Joseph JA. Structure-activity relationships of quercetin in antagonizing hydrogen peroxide-induced calcium dysregulation in PC12 cells. Free Radic Biol Med. 1999;27(5-6):683-694.

9. Witte MB, Barbul A. Arginine physiology and its implication for wound healing. Wound Repair Regen. 2003;11(6):419-423.

10. Wu G, Jaeger LA, Bazer FW, Rhoads JM. Arginine deficiency in preterm infants: biochemical mechanisms and nutritional implications. J Nutr Biochem. 2004;15(8):442-451.

11. Stechmiller JK, Childress B, Cowan L. Arginine supplementation and wound healing. Nutr Clin Pract. 2005;20(1):52-61.

12. Al-Rasheed NM. Prophylactic Role of $\alpha$-Lipoic acid and vitamin e against zinc oxide nanoparticles induced metabolic and immune disorders in rat's liver. European Rev Med Pharmacology Sci. 2014;18: 1813-1828.

13. Abdelhalim M, Moussa S, Qaid H. The protective role of quercetin and arginine against hepatotoxicity induced by gold nanoparticles. Int J Nanomedicine. 2018;13:2821-2825.

14. Griffith OW. Determination of glutathione and glutathione disulfide using glutathione reductase and 2-vinylpyridine analyst. Biochem. 1980;106:207-212.
15. Oberdörster G, Maynard A, Donaldson K, et al. Principles for characterizing the potential human health effects from exposure to nanomaterials: elements of a screening strategy. Part Fibre Toxicol. 2005;2:8:8.

16. Jain TK, Reddy MK, Morales MA, Leslie-Pelecky DL, Labhasetwar V. Biodistribution, clearance, and biocompatibility of iron oxide magnetic nanoparticles in rats. Mol Pharm. 2008;5(2):316-327.

17. Burns AA, Vider J, Ow H, et al. Fluorescent silica nanoparticles with efficient urinary excretion for nanomedicine. Nano Lett. 2009;9(1): $442-448$.

18. Schipper ML, Iyer G, Koh AL, et al. Particle size, surface coating, and PEGylation influence the biodistribution of quantum dots in living mice. Small. 2009;5(1):126-134.

19. Bérubé K, Balharry D, Sexton K, Koshy L, Jones T. Combustion-derived nanoparticles: mechanisms of pulmonary toxicity. Clin Exp Pharmacol Physiol. 2007;34(10):1044-1050.

20. Semmler M, Seitz J, Erbe F, et al. Long-term clearance kinetics of inhaled ultrafine insoluble iridium particles from the rat lung, including transient translocation into secondary organs. Inhal Toxicol. 2004; 16(6-7):453-459.

21. Chen Z, Meng H, Xing G. Acute toxicological effects of copper on engineered nanomaterials. Nat Nanotechnol. 2007;2:469-478.

22. Mostafavi-Pour Z, Zal F, Monabati A, Vessal M. Protective effects of a combination of quercetin and vitamin $\mathrm{E}$ against cyclosporine A-induced oxidative stress and hepatotoxicity in rats. Hepatol Res. 2008;38(4): 385-392.

23. Hushmendy S, Jayakumar L, Hahn AB, Bhoiwala D, Bhoiwala DL, Crawford DR. Select phytochemicals suppress human T-lymphocytes and mouse splenocytes suggesting their use in autoimmunity and transplantation. Nutr Res. 2009;29(8):568-578.

24. Huang CC, Tsai SC, Lin WT. Potential ergogenic effects of L-arginine against oxidative and inflammatory stress induced by acute exercise in aging rats. Exp Gerontol. 2008;43(6):571-577.

25. Faddah LM, Abdel Baky NA, Al-Rasheed NM, Al-Rasheed NM, Fatani AJ, Atteya M. Role of quercetin and arginine in ameliorating nano zinc oxide-induced nephrotoxicity in rats. BMC Complement Altern Med. 2012;12:60.

26. Sanhueza J, Valdes J, Campos R, Garrido A, Valenzuela A. Changes in the xanthine dehydrogenase/xanthine oxidase ratio in the rat kidney subjected to ischemia-reperfusion stress: preventive effect of some flavonoids. Res Commun Chem Pathol Pharmacol. 1992;78(2): 211-218.

27. Satyanarayana PS, Singh D, Chopra K. Quercetin, a bioflavonoid, protects against oxidative stress-related renal dysfunction by cyclosporine in rats. Methods Find Exp Clin Pharmacol. 2001;23(4):175-181.

28. Utley HG, Bernheim F, Hochstein P. Effect of sulfhydryl reagents on peroxidation in microsomes. Archives of Biochemistry and Biophysics. 1967;118(1):29-32.
International Journal of Nanomedicine

\section{Publish your work in this journal}

The International Journal of Nanomedicine is an international, peerreviewed journal focusing on the application of nanotechnology in diagnostics, therapeutics, and drug delivery systems throughout the biomedical field. This journal is indexed on PubMed Central, MedLine, CAS, SciSearch ${ }^{\circledR}$, Current Contents ${ }^{\circledR} /$ Clinical Medicine,
Dovepress

Journal Citation Reports/Science Edition, EMBase, Scopus and the Elsevier Bibliographic databases. The manuscript management system is completely online and includes a very quick and fair peer-review system, which is all easy to use. Visit http://www.dovepress.com/ testimonials.php to read real quotes from published authors. 